\title{
PHORETIC ASSOCIATIONS BETWEEN HYPOPI OF ACARUS NIDICOLOUS (ACARI, ASTIGMATA, ACARIDAE) AND FLEAS OF BRITISH SMALL MAMMALS
}

\author{
D. P. BRITT* and D. H. MOLYNEUX**
}

During examination of fleas from various small mammals in Cheshire and South Wirral, England a number of phoretic associations have been observed involving deutonymphs, hypopi, of Acarus nidicolous. Several examples of phoresy involving mites and the fleas of small mammals in continental Europe have been described (Fain \& Beaucournu, 1972) but although such associations are probably not uncommon with British fleas (Miriam Rothschild, pers. comm. to D. H. M.) few reports have appeared in published literature.

The first of the observations recorded here was made in 1978 during an investigation of the parasites of grey squirrels (Sciurus carolinensis Gmelin) from Delamere Forest in Cheshire (Britt \& Molyneux, 1979). Ninety-five per cent of 150 adult and juvenile squirrels were found to be infested with the flea Orchopeas howardi (Baker) and many of these were seen to be carrying hypopi of $A$. nidicolous attached to both thoracic and abdominal regions, often inserted beneath the overlapping dorsal and ventral exoskeletal plates, sclerites (fig. 1, 2, 3, 4). Up to 11 hypopi were counted on a single flea.

Several hundred hypopi of the same species were recovered from each of four dreys collected from the same area at the time of the parasite survey and one of only seven adult $O$. howard $i$ found in the dreys carried four of the nymphs.

In May/June, 1980 five hedgehogs (Erinaceus europaeus Linn.) and 14 woodmice (Apodemus sylvaticus (Linn.)), trapped at or near the University of Liverpool's Veterinary Field Station on Wirral, were examined. The hedgehogs each hosted the flea Archaeopsylla erinacei (Bouché) and on four of the five, hypopi of $A$. nidicolous were found in association with the fleas.

Fleas, from one to five in number, were recovered from all but one of the A. sylvaticus. Four species were represented: Ctenophthalmus nobilis vulgaris Smit, C. bisoc-

* Department of Veterinary Parasitology, Liverpool School of Tropical Medicine, Pembroke Place, Liverpool L3 5QA, England.

** Department of Biology, University of Salford, Salford M5 4WT, England.

Accepté le 20 septembre I982. 


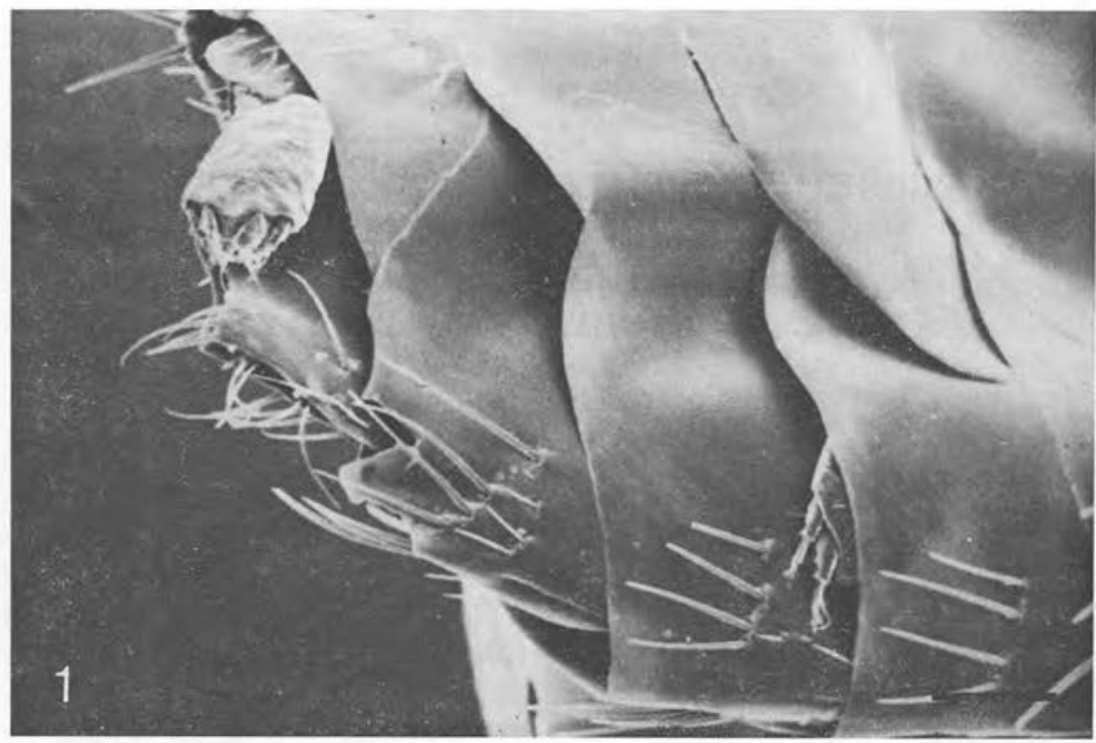

Fig. I. - Two hypopi (Acarus nidicolous) attached to the abdomen of Orchopeas howardi. One has become dislodged from its normal position below the overlapping exoskeletal plates. $\mathrm{Bar}=100 \mu \mathrm{m}$.

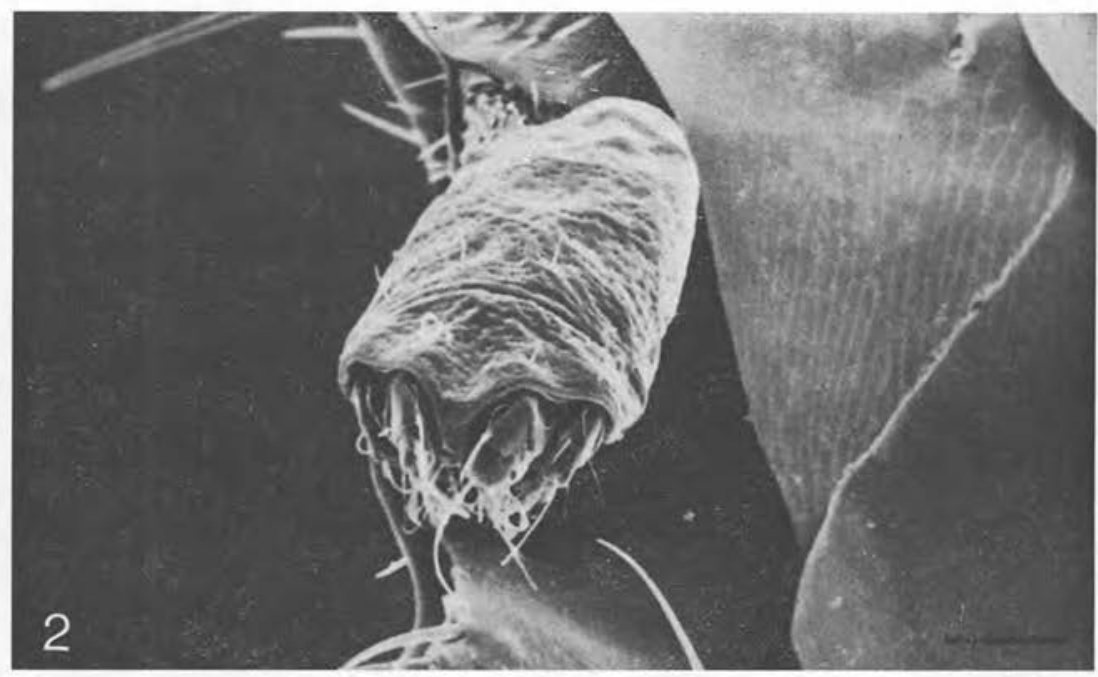

FIG. 2. - Enlargement of the dislodged hypopus from I attached at terminalia of flea. Bar $=40 \mu \mathrm{m}$. 


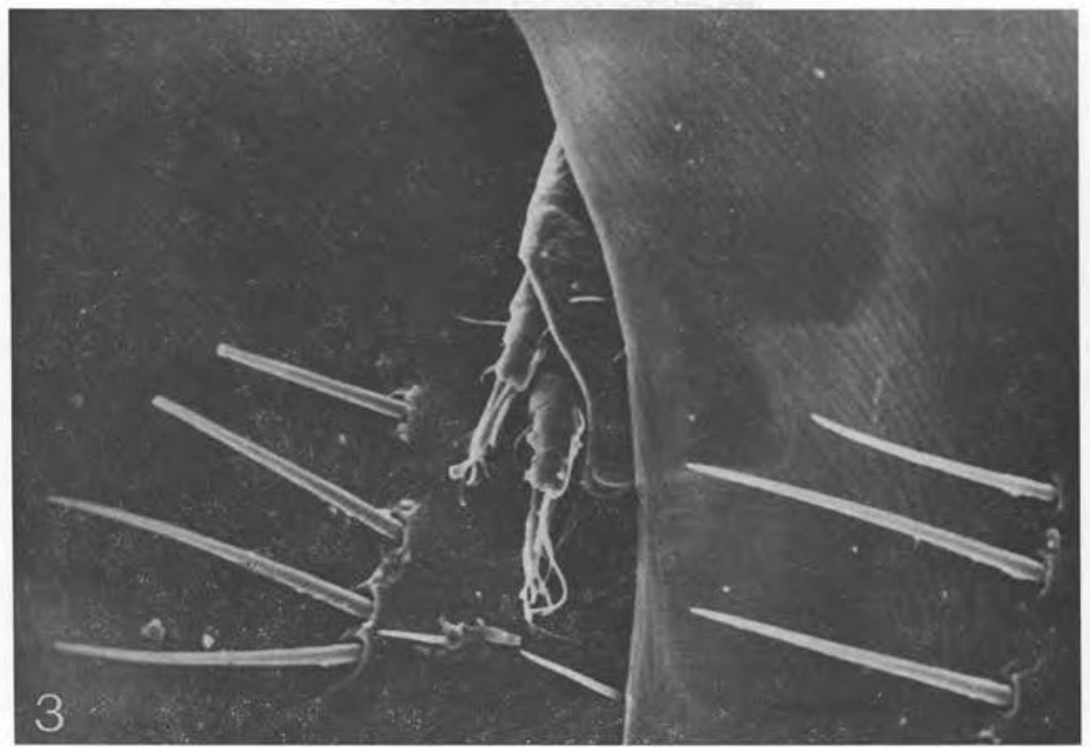

FIG. 3. - Enlargement of the hypopus from I partly concealed beneath sternite V. Bar $=4^{\circ} \mu \mathrm{m}$.

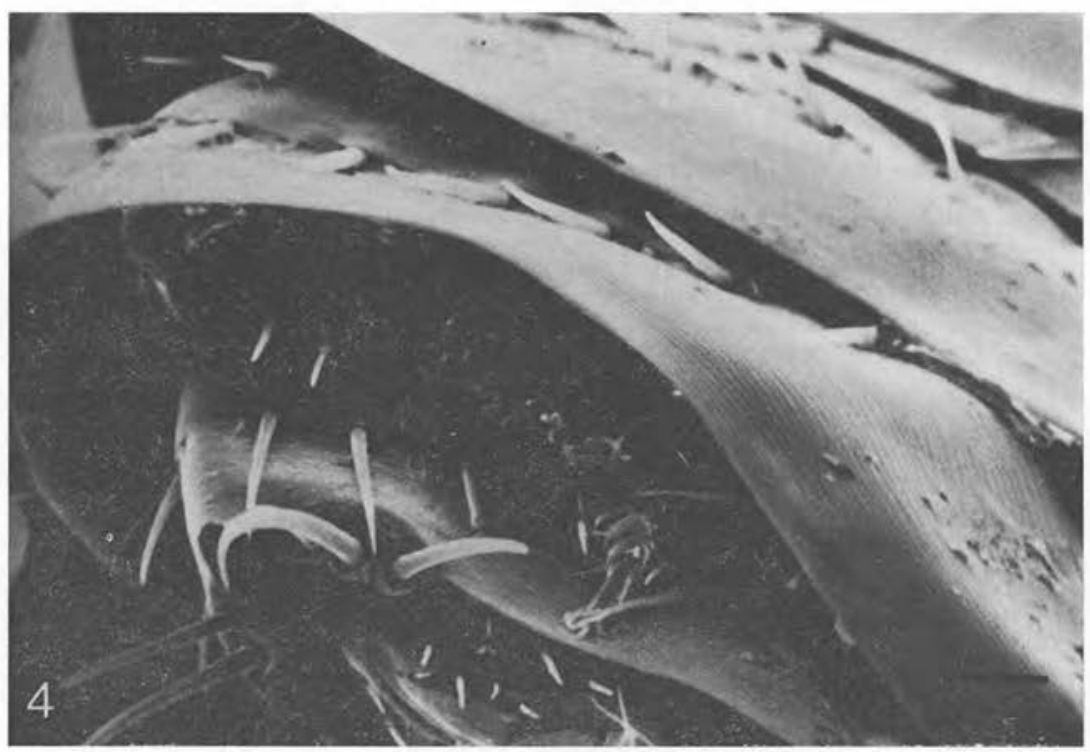

FIG. 4. - Another hypopus beneath tergum VII of another $O$. howardi. $\mathrm{Bar}=40 \mu \mathrm{m}$. 
todentatus occidentalis Smit, Megabothris walkeri (Rothschild) and M. turbidus (Rothschild), the former being most common. A female C. n. vulgaris was found to be carrying 5 hypopi of $A$. nidicolous.

Nymphs of A. nidicolous appear to occur in phoretic association with fleas of small mammals (chiefly rodents and insectivores) more frequently than those of other mites. They have been recorded associated with four small mammal fleas, including A. e. erinacei, in Belgium (Cooreman, 1944) and with eight species of rodent fleas (including C.n. vulgaris) and six fleas from insectivores or their nests, including again A. e. erinacei, in France (Fain \& Beaucournu, op. cit.). Orchopeas howardi however, does not appear to have been reported before as serving as an host to any phoretic mite. Distribution of the squirrel host of $O$. how ard $i$ in Europe is, of course, restricted to Britain and Ireland. It is not known if the flea-mite association described here occurs in the squirrel's native habitat (the eastern states of U.S.A. and Canada) or in South Africa where it has also been introduced.

Rothschild (1969) reports one flea-mite association in which the host appears to have suffered injury as a result of the transported mite feeding, or attempting to feed, on it. Hypopial nymphs as non-feeding stages will not be responsible for such damage but they may impair the efficiency of their hosts mechanically, especially if very numerous. No such impairment was noticed in the examples reported here.

We are indebted to Professor A. J. Fain of Antwerp for determining the identity of the Acarus nidicolous nymphs, and to Mr. D. Lavin for preparation of the scanning electron micrographs.

\section{REFERENCES}

Britt D. P., Molyneux D. H.: Parasites of Grey Squirrels in Cheshire, England. J. Parasitol., I979, 65, 408 .

Cooreman J.': Notes et Observations sur les Acariens. III. Bull. Mus. Roy. Hist. Nat. Belg., I944, $X X, \mathrm{I}_{2}-\mathrm{I} 4$.

Farn A., Beaucournu J. C.: Notes sur les Hypopes Vivant en Association Phorétique sur les Puces en France. Acarologia, 1972, 13, 522-531.

Rothschild M.: Notes on Fleas. Proc. Brit. Ent. Nat. Hist. Soc., r969, 9-16. 